https://doi.org/10.30910/turkjans.725826

\begin{tabular}{c}
\hline TÜRK \\
TARIM ve DOĞA BiLIMLERI \\
DERGISI
\end{tabular}

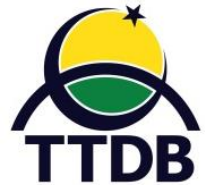

www.dergipark.gov.tr/turkjans

Araştırma Makalesi

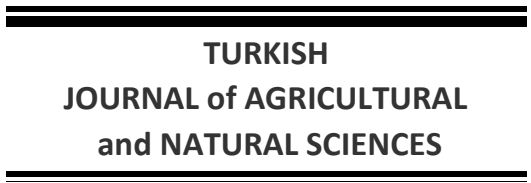

TURKISH

and NATURAL SCIENCES

\title{
Reşadiye (A6, Tokat) ve Çevresindeki Bitkilerin Etnobotanik Özellikleri
}

\author{
Erkan YÜZBAŞIOĞLU1 ${ }^{1}$, Tülay TÜTENOCAKLI ${ }^{2 *}$, İsmet UYSAL ${ }^{3}$ \\ ${ }^{1}$ Çanakkale Onsekiz Mart Üniversitesi, Fen Bilimleri Enstitüsü, Biyoloji Anabilim Dalı, Çanakkale, Türkiye \\ ${ }^{2}$ Çanakkale Onsekiz Mart Üniversitesi, Lapseki MYO, Tıbbi ve Aromatik Bitkiler Pr., Çanakkale, Türkiye \\ ${ }^{3}$ Çanakkale Onsekiz Mart Üniversitesi, Fen-Edebiyat Fakültesi, Biyoloji Bölümü, Çanakkale, Türkiye \\ *Sorumlu yazar: t_tutenocakli@hotmail.com
}

Geliş Tarihi: 27.01.2020 Düzeltme Geliş Tarihi: 06.03.2020 Kabul Tarihi: 10.03.2020

\begin{abstract}
Özet
Reşadiye (A6, TOKAT) ilçe merkezi ile 12 belde ve 48 köy olmak üzere toplamda 61 yerleşim yerinde yapılan etnobotanik araştırmada, 120 kaynak kişi ile görüşülmüş ve bölgeden 40 familyaya ait 85 bitki taksonu toplanmış ve bu bitkilerin kullanım amaçları ve kullanım şekilleri belirlenmiştir. Ağılıklı olarak Rosaceae (\%18), Brassicaceae, Lamiaceae ve Asteraceae (\%6), Boraginaceae (\%5) familya üyeleri kullanılmaktadır. Bu bitkilerden sırasıyla 61 takson gıda (\%72), 33 takson halk ilacı - tıbbi (\%39), 20 takson hem tıbbi hem de gıda, 2 takson süs (\%2) ve 13 taksonun da diğer amaçlarla (\%15) kullanıldığı saptanmıştır.
\end{abstract}

Anahtar Kelimeler: Etnobotanik, Reşadiye, Tokat

Ethnobotanical Properties of the Plants in Reşadiye (A6, Tokat) and its Environs

\begin{abstract}
An ethnobotanical investigation was made in order to determine the plants used by the local people in the region of Reşadiye (A6, TOKAT). For this purpose, the center of Reşadiye, 12 towns and 48 villages; totally 61 settlements have been visited with 120 informants. During the field work 85 plant species belonging to the family of 40 were collected and the uses and purpose of uses of these plants were determined. Family members of Rosaceae (18\%), Brassicaceae, Lamiaceae and Asteraceae (6\%), Boraginaceae (5\%) are mainly used. The findings of the research are presented in detail in the article. According to the results of this study total 85 taxa which have ethnobotanical usage, were identified. Among these plants, 61 taxa (72\%), 33 taxa folk medicine (39\%), 20 taxa were used for both medical and food, 2 taxa (2\%) and 13 taxa for other purposes (15\%).
\end{abstract}

Key Words: Ethnobotany, Reşadiye, Tokat

\section{Giriş}

Etnobotanik terimi ilk kez, John Harshberger (1895) tarafından "ilkel ve aborjin insanlar tarafından kullanılan bitkiler" konulu çalışmasında bir terim olarak önerilmiştir (Wickens, 1990). "Bitkilerin yerel halk tarafından kullanımı" bir diğer deyişle insanlar ile bitkiler arasındaki ilişkileri inceleyen bir bilim dalı olarak tanımlanmaktadır. (Yıldırımlı, 2004).

insanlığın varoluşundan beri yabani bitkiler yerel halk tarafından kullanılmış, değişik amaçlarla kullanılan bu bitkilerin kullanım bilgisi nesilden nesile aktarılmıştır.

Bitkilerin yerel halk tarafından kullanımlarının tarihsel geçmişi, insanların bitki kullanım geleneği hakkında çok önemli fikirler vermektedir. Doğadan toplanan yararlı bitkiler ardından kültüre alınarak tarımı yapılmıştır. Tedavi için kullanılan bitkileri ele alan araştırmalar bu konuda öncelik almış olup, şifa amacıyla kullanılan bitkiler büyük önem 
taşımaktadır. Günümüzde tedavide kullanılan, birçok etken maddenin araştırılmasına öncülük eden, bitkilerin kullanımı üzerine kurulu etnobotanik araştırmalar olmuştur (Farnsworth, 1990).

Anadolu halkının yabani bitkileri ilaç olarak kullanışı çok eski devirlere kadar uzanmaktadır. Hititler dönemi tıbbi tabletlerinde bulunan reçete formüllerinde kayıtlı bitki adları da bunun kanıtıdır. Bu dönemlerde yabani bitkilerden yararlanıldığı gibi, bazı önemli tıbbi bitkiler, drog elde etmek için yetiştirilmekteydi. Kırsal bölgelerde, ilaç hazırlamak için genellikle çevrede yetişen veya kültüre aldıkları bitkiler kullanılmaktaydı (Baytop, 1999).

Türkiye kültürel mirasın zenginliği ve 11707 taksondan oluşan zengin bir floraya ev sahipliği yapmaktadır. 167 familya, 1320 cins, 9996 tür, 1989 alt türe sahip olan ülkemizde 3649 takson endemiktir (Davis, 1965-1985; Davis ve ark., 1998; Güner ve ark., 2012). Zengin bir floraya sahip ülkemizde yetişen bitkiler düşünüldüğünde etnobotanik çalışmalardan elde edilecek bilgilerin önemi daha iyi anlaşılmaktadır.

Doğadan toplanan bitkilerden yararlanma konusu günden güne artış göstermekte ve dünyadaki çeşitli ülkelerde etnobotanik araştırmalar kapsamında bu bitkiler tespit edilmekte, yayın haline dönüştürülerek kayıt altına alınmaktadır. Türkiye'de başlatılan araştırmalar bölgesel olduğu gibi il ve ilçe bazında da yürütülmektedir. Çolakoğlu ve Tömek (1975)'in Ege Bölgesi'nde, Öztürk ve Özçelik (1991)'in Doğu Anadolu Bölgesi'nde, Ertuğ-Yaraş (1996) ve Ertuğ (2000)'un İç Anadolu Bölgesi'nde, Bayrak-Özbucak ve ark. (2006)'nin Karadeniz Bölgesi'nde, Fakir ve ark. (2009)'nin Batı Akdeniz Bölgesi'nde yapmış oldukları bölgesel araştırmalar yanında il ve ilçe bazında çalışmalar da gün geçtikçe artmaktadır. Sadıkoğlu (1998), Cumhuriyet Dönemi Etnobotaniği Araştırma Arşivi adlı çalışma; Ospankulova (2005), Türkiye Etnobotanik Araştırmalar Veri Tabanı adlı araştırmalar da etnobotanik anlamda yapılacak çalışmalara kaynak oluşturacak önemli çalışmalardandır. Ayrıca ülkemizde son yıllarda doktora ve yüksek lisans çalışmalarında bitkilerin etnobotanik açıdan değerlendirilmesi ile ilgili konuların seçilmesi de bu konuda bir yönelimin olduğunu göstermektedir.

Ülkemiz zengin bir flora ve kültür mirasına sahip olmasına rağmen, Anadolu'da yabani bitkilerin halk arasındaki tedavi, gıda ve diğer amaçlarla kullanıışını konu alan bilimsel nitelikte etnobotanik çalışmaların sayısı son yıllarda artmaya başlamıştır.

Köyden kentlere göç, sağlık hizmetlerine daha kolay erişim, yol ve ulaşım araçlarındaki gelişmeler gibi faktörlere genç nesillerin ilgisizliği de eklenince halk ilâcı ve etnobotanik saha çalışmalarının yapılması giderek zorlaşmakta, etnobotanik bilgiler gün geçtikçe kaybolmaktadır. Bu nedenlerle bu bilgilerin kayıt altına alınabilmesi için organize ve daha kapsamlı bilimsel nitelikli çalışmaların yapılarak bu bitkilerin kayıt altına alınmaları son derece önemlidir.

$\mathrm{Bu}$ araştırma, yerel halkın geleneksel olarak kullandığı bitkilerin sınıflandırılması ve kullanım biçimi ile ilgili olarak Tokat ilinin Reşadiye yöresinde gerçekleştirilmiş bir çalışmadır. Araştırma yöresi olan Reşadiye ilçesinde doğrudan yapılmış bir çalışma bulunmamaktadır. İlçenin bağı bulunduğu Tokat ilinde yapılan bir çalışmada Erodium cicutarium (L.) L'Hér., Fumaria officinalis L., Plantago lanceolata L., Rumex acetosella L., Scandix pecten-veneris L., Stellaria media (L.) Vill., Tragopogon pratensis L. subsp. pratensis taksonlarının etnobotanik özellikleri incelenmiş, bu taksonların geleneksel tedavide kullanıldığını ve çiçeklendikten sonra hayvan yemi olarak kullanıldıklarını ifade etmişlerdir (Ulcay ve Şenel, 2020). Tokat ilinin Reşadiye ilçesinde kullanılan yabani bitkiler ile ilgili bilimsel çalışmaların sınırlı ve yetersiz olması nedeniyle yapılan bu etnobotanik çalışmada; Tokat ilinin Reşadiye ilçesinde yaşayan yerel halkın geleneksel olarak tükettikleri doğal bitkilerin tespit edilmesi ve halkın tarihsel kültüründen bugüne yansıyan bitki kullanım bilgisinin gün ışığına çıkarılması ve bundan sonra yapılacak çalışmalara kaynak oluşturması amaçlanmıştır. Ayrıca çalışma sonucunda elde edilen veriler ile hem Türkiye Florası hem de "Etnobotanik Veri Tabanı" çalışmalarına katkı sağlayacağı düşünülmektedir. 


\section{Materyal ve Yöntem}

Araştırmanın materyalini, Reşadiye (A6,Tokat) ilçe merkezi ile 12 belde ve 48 köy olmak üzere 61 yerleşim yerinde toplanan bitki örnekleri oluşturmaktadır.

\section{Araştırma Alanının Coğrafik Yapısı}

Araştırma bölgesi olan Tokat'ın Reşadiye ilçesi orta Karadeniz bölgesinde olup, Türkiye grid sisteminde A6 karesinde yer almaktadır (Şekil 1). Kuzeyinde Aybastı ve Gölköy; güneyinde Almus ve Doğanşar, doğusunda Koyulhisar ve Mesudiye; batısında Niksar ve Başçiftlik ilçeleri bulunmaktadır. Coğrafi olarak $40^{\circ} 31^{\prime}$ kuzey enlemleri ile $37^{\circ} 06^{\prime}$ doğu boylamları arasında bulunmaktadır. Kelkit Irmağı kıyısında kurulmuş bulunan Reşadiye'nin en yüksek tepesi $2183 \mathrm{~m}$ ile Erdem Baba Tepesi'dir. Bunu, Küçük Erdem Tepesi (2113 m), Kabaktepe (2037 m), Çal Tepesi (2022 m), Mektep Tepesi, Tömbül Tepesi ve Lalelik Tepesi izler. Bu yüksekliklerin tümü Günüş Dağı'nda bulunmaktadır. İlçenin arazi yapısının dağlık olması nedeniyle geniş ovası bulunmamaktadır. Ancak ovacık, meydanlar, yazı ve düzlükleri ekim ve dikime müsaittir. Reşadiye ilçesi yaylalar yönünden oldukça zengindir. 44 yaylanın içerisinde en çok bilinen yaylası Selemen yaylasıdır (Yüzbaşıoğlu, 2010).

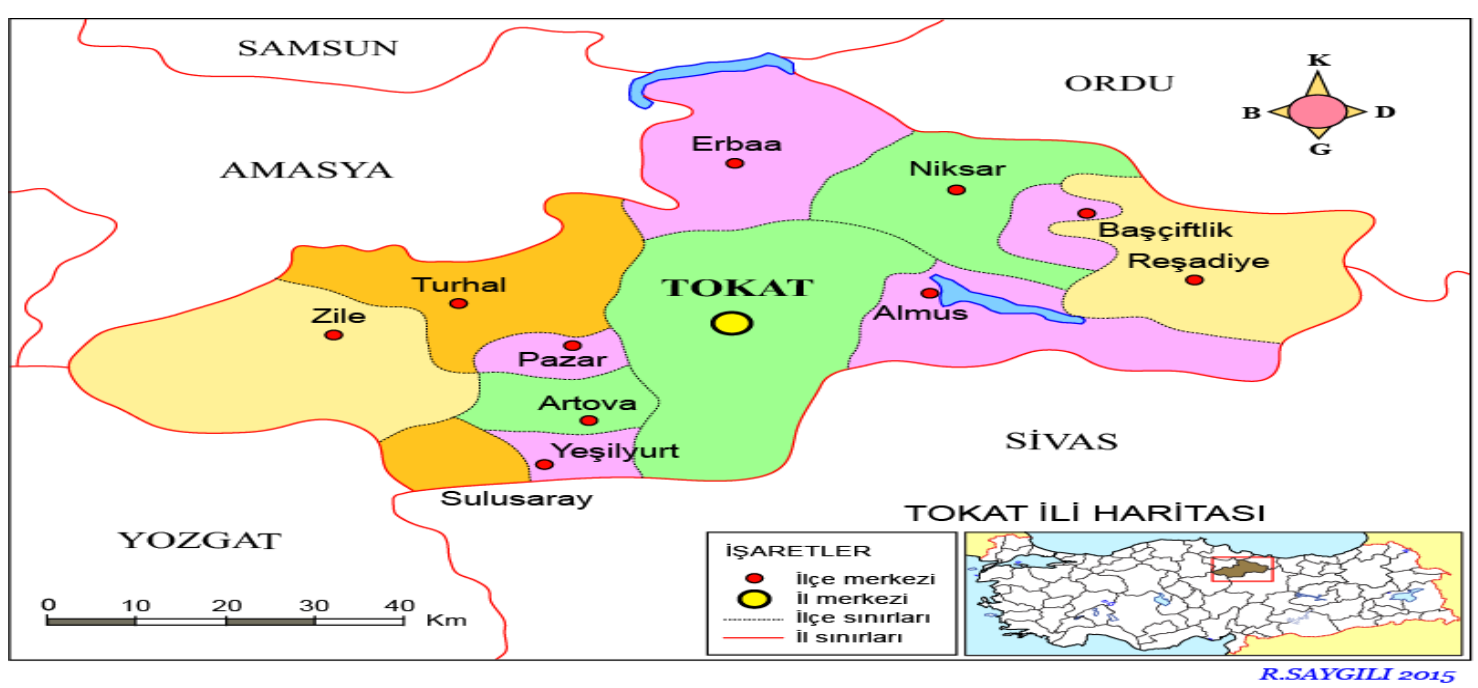

Şekil 1. Tokat ili ve Reşadiye ilçesinin Türkiye haritasındaki yeri (Saygılı, 2015).

İlçede kenarında kurulduğu Kelkit Çayı dışında Tozanlı Çayı, Delice Çayı, Tombalak, Köy ve Reşit dereleri mevcuttur. Ayrıca doğal güzellikler bakımından zengin olan Gındıralı, Gödölöş, Göllüköy, Kurt, Mehmetbey, Sülük, Zınav gölü de Reşadiye'nin coğrafi zenginlikleridir.

\section{Yöntem}

Bu çalışmada, Reşadiye ilçe merkezi, 12 belde ve 48 köy olmak üzere toplamda 61 yerleşim alanında, kendilerine ulaşılan 120 kaynak kişi ile yüz yüze görüşülmüş ve görüşmede bir mülakat formu kullanılmıştır. Araştırma yapılan Reşadiye yöresindeki köyler Şekil 2'de harita üzerinde gösterilmiştir. Bitkileri etnobotanik amaçla toplayan, kullanan, hem toplayan hem kullanan ve ticari amaçlı olarak kullanan kişiler öncelikle tespit edilmiştir. Temel bilgileri içeren etnobotanik formu esas alınarak uygulanan mülakat ile kaynak kişilerin bilgilerine başvurulmuştur. Araştırma konusu ile ilgili bilgiler, ilçede ve çevresindeki köylerde yaşayan yerel halktan sağlanmaya çalışılmıştır ve bu amaçla özellikle halk hekimliği yapan veya bitki ticaretiyle uğraşan kişilere ulaşmaya gayret edilmiştir. Mülakat yapılan kişilere etnobotanik formu koleksiyon bilgileri kapsamında öncelikle bitkinin yerel ismi, toplandığı lokalite, kullanım amacı, kullanılan kısımları, kulanım biçimi sorulmuştur. Ayrıca etnobotanik araştırma formu ile kullanıcı bilgileri kapsamında bilgi alınan yöre halkının adı, soyadı, yaşı, yöresi, etnik durumu (kültürel konumu), medeni hali, öğrenim durumu ve bitkilerle ilgili sahip olduğu diğer bilgiler de tespit edilmeye çalışılmıştır. Mülakatta kullanılan ek sorular daha sonra istatistik değerlendirmede kullanılmıştır. Arazi çalışmaları sırasında yöreyi tanıyan kılavuz olabilecek kaynak kişilerden de yararlanılmıştır. 


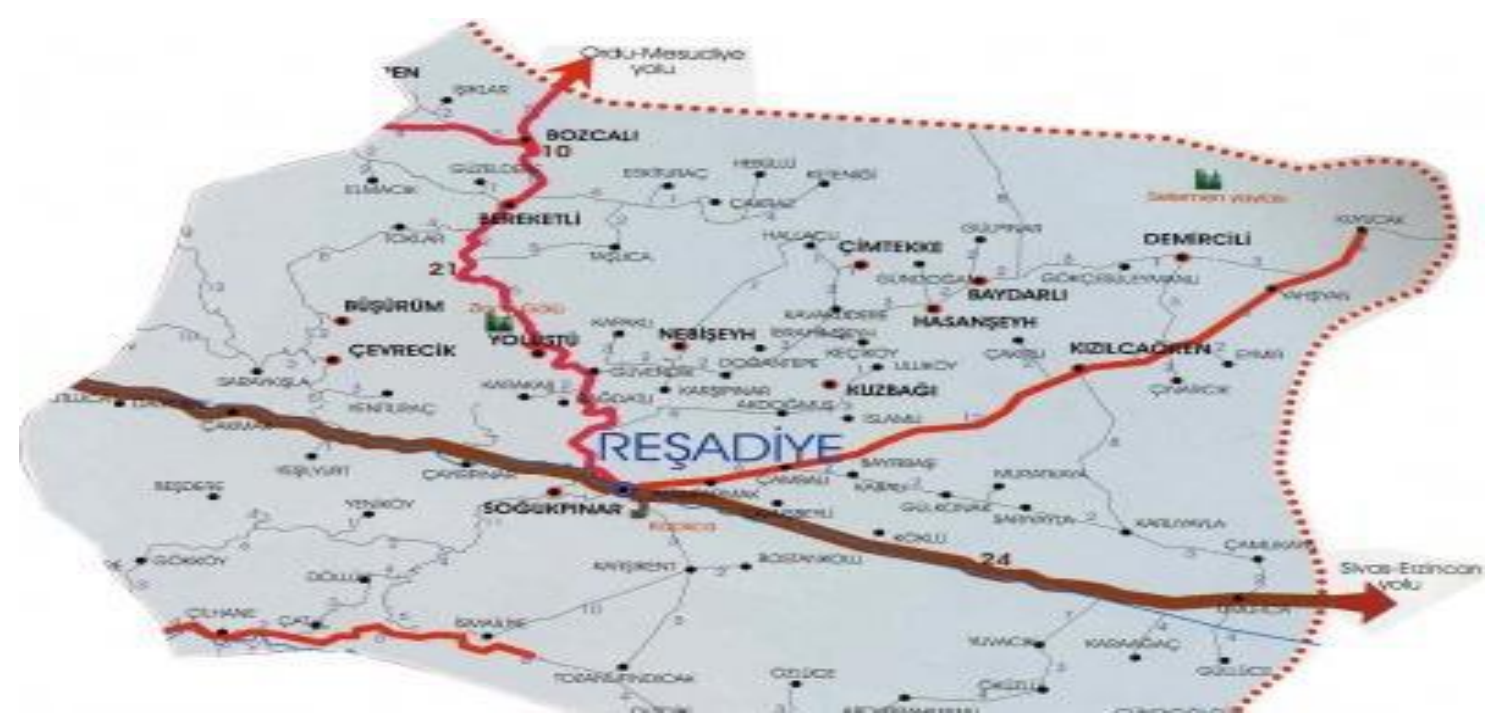

Şekil 2. Reşadiye ilçesinin haritası ve köylerin yerleşimi.

Daha sonra elde edilen veriler doğrultusunda, bilgi kaynağı kaynak kişiler ile vejetasyon dönemlerinde birlikte arazi çalışması yapılarak bitkilere ulaşılmıştır. Ayrıca bitkilerin toplandığı lokalitenin yükseklik ve koordinat bilgileri GPS (Global Positioning System) sistemi ile belirlenerek kaydedilmiştir. Bitkilerin toplandığı lokalitelerin genel özelliklerini ve habitat özelliklerini belgelemek amacıyla fotoğraflar çekilerek etnobotanik nitelikli görüntülerin kayıt altına alınması sağlanmıştır. Bitkiler "Flora of Turkey and the East Aegean Islands" (Davis, 1965-1985; Davis ve ark., 1988) yardımı ile teşhis edilmiştir. Toplanan bitkiler herbaryum tekniklerine göre preslenip kurutulmuş ve herbaryum örneği haline getirilmiştir. Bitkilerin Türkçe bilimsel adları ve doğruluğu Güner ve ark. (2012)'nin hazırlamış olduğu "Türkiye Bitkileri Listesi (Damarlı Bitkiler)" kitabından kontrol edilmiştir. Etnobotanik kullanıma sahip bitkilerin bilimsel isimleri, familyaları ile birlikte kullanım amaçları, kullanılan organları, kullanım şekilleri listelenmiştir.

\section{Araştırma Bulguları ve Tartışma}

$\mathrm{Bu}$ araştırma ile Reşadiye (Tokat) ve çevresindeki 85 bitkinin yerel halk tarafından farklı amaçlarla kullanıldığı ortaya çıkartılmıştır.
Reşadiye ve çevresinde etnobotanik kullanıma sahip taksonların listesi Çizelge 1'de verilmiştir. Rosaceae'den 15; Asteraceae (Compositae), Brassicaceae (Cruciferae), Lamiaceae (Labiatae)'den 5'er, Boraginaceae'den 4, Amaranthaceae, Asparagaceae, Caryophyllaceae, Polygonaceae ve Solanaceae'den 3'er, Amaryllidaceae, Apiaceae, Betulaceae, Cannabaceae, Malvaceae ve Plantaginaceae 'den 2'şer ve Anacardiaceae, Colchicaceae, Cornaceae, Cucurbitaceae, Cupressaceae, Fabaceae, Fagaceae, Gentianaceae, Grossulariaceae, Juncaceae, Juglandaceae, Liliaceae, Moraceae, Onagraceae, Orchidaceae, Pedaliaceae, Pinaceae, Poaceae, Portulacaceae, Ranunculaceae, Salicaceae, Santalaceae, Urticaceae ve Vitaceae'den 1'er takson olmak üzere toplam 40 familyaya ait 85 takson belirlenmiştir (Şekil 3). Ağırlıklı olarak Rosaceae (\%18), Asteraceae, Brassicaceae ve Lamiaceae (\%6), Boraginaceae (\%5) familya üyelerinin kullanıldığı görülmektedir. Araştırma bölgesinde Rosaceae familya üyelerinin etnobotanik anlamda ağırlıklı kullanıldığı görülmüştür. Bu durumunda bizi bölgenin coğrafi ve ekolojik koşullarının bir sonucu olduğu yorumuna götürmektedir. 


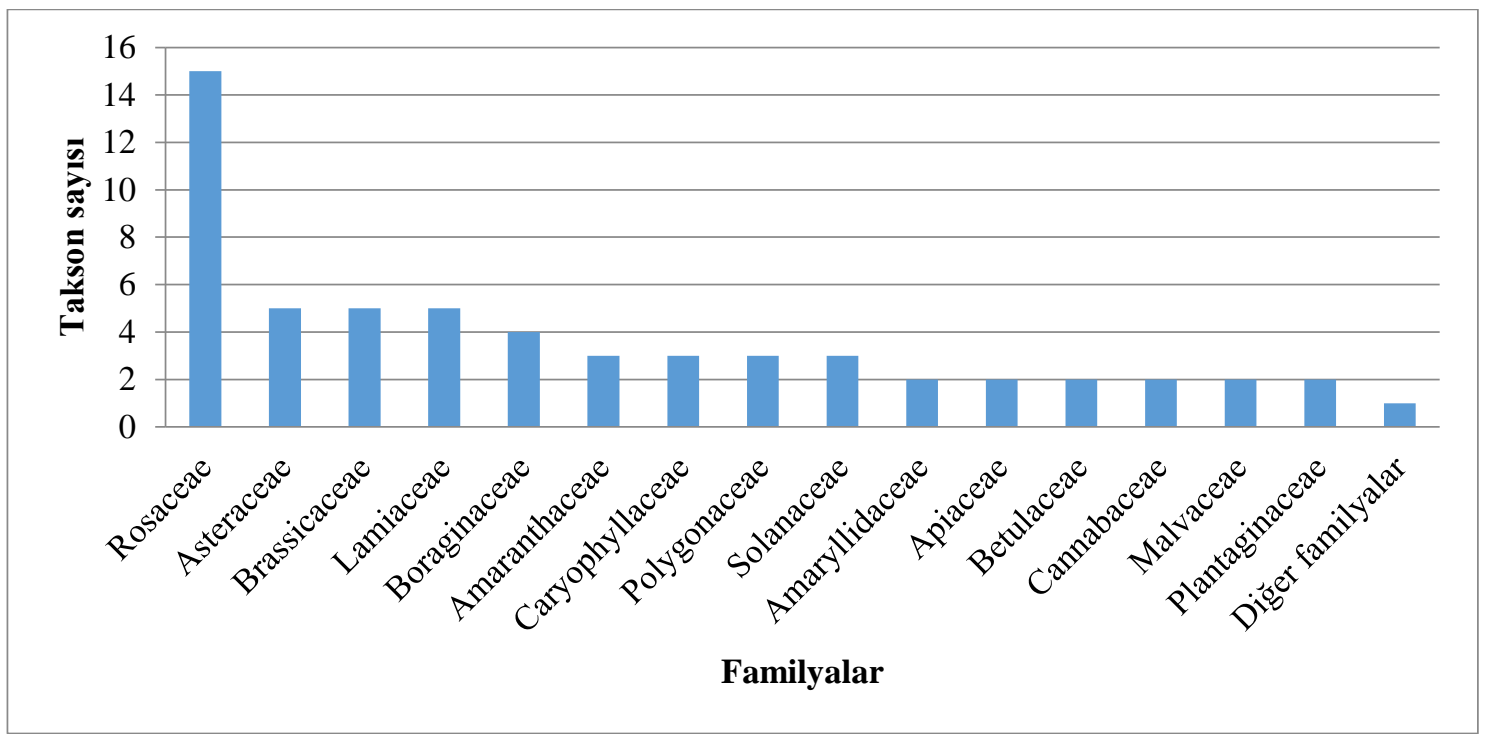

Şekil 3. Bitki kullanımına göre familya dağılımı.

Yörede çeşitli amaçlarla kullanıldığı saptanan 85 taksondan 61 takson gıda ve baharat olarak, 33 takson tıbbi amaçlı, 20 takson hem tıbbi hem gıda olarak, 5 takson yakacak olarak, 2 takson süs bitkisi olarak ve 13 takson diğer amaçlar için kullanılmaktadır (Şekil 4). Kullanım amaçları ele alındığında büyük çoğunluğun gıda amaçlı kullanım (\%72) olduğu göze çarpmaktadır. Tıbbi bitki kullanımı ise \%39 oranındadır. Yakacak $\% 6$ ve süs bitkileri $\% 2$ ile kullanımı daha azdır. Diğer kullanım amaçları ise \%15 olarak tespit edilmiştir. Gıda olarak tüketilen bitkilerin fazlalığının nedeni, yöre halkının ekonomik bakımdan alım gücünün zayıf olması ve bu bitkilerin yöresel bir gelenek olarak kullanılması göze çarpmaktadır. Bu yörede kullanılan tıbbi bitkilerin oranının Türkiye'nin çeşitli yerlerinde yapılan etnobotanik araştırmalar incelendiğinde takson sayısı ve kullanım amacı açısından daha az olduğu saptanmıştır. Ebeveynlerden aktarılan bilgilere ilginin az olduğundan ve gözlemlerimize göre de yöre halkının modern tıbba yönelmesinin, bizi bu oranın düşük olmasında etken olduğu sonucuna götürmektedir.

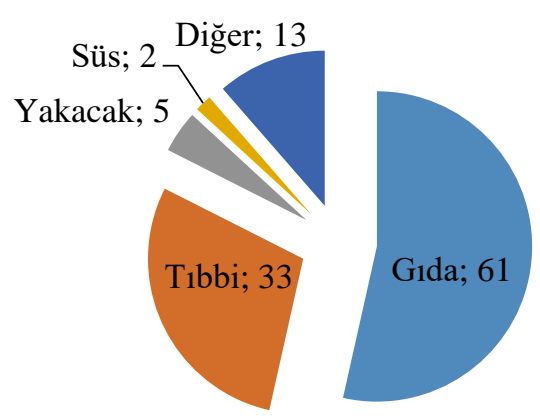

Şekil 4. Bitkilerin kullanım amaçlarına göre dağılımı.

Süs bitkisi olarak 2 bitki türü kullanılmaktadır. Bu bitki türleri Dianthus calocephalus Boiss. ve Scilla bifolia L.'dır. Yöre halkının süs bitkilerine eğilimi yok denecek kadar azdır. Yakacak olarak 5 bitki türü kullanılmaktadır ve bu bitki türleri; Carpinus betulus L., Juniperus oxycedrus L., Pinus brutia Ten., Prunus mahaleb L. ve Quercus coccifera L.'dır. Yakacak olarak kullanılan orman, ağaç ve çalıları kontrollü şekilde tüketilmektedir. Kullanılan bitkilerin yaygın olmamasının ana nedeni yerel halkın bu konudaki bilinçli 
davranışı ve kamu kontrol uygulamalarının sağlıklı oluşudur. Diğer bitki kullanımlarında 13 bitki yer almaktadır. Bu bitki türlerinden arıcılıkta kullanılan Gagea taurica Steven, Helleborus orientalis Lam. ve Luzula spicata (L.)
DC. türleri yörede genellikle yaylalarda yaygın biçimde yetişmekte ve mevsimi geldiğinde üreticilerin arı kovanlarını bu yaylalara taşıdıkları görülmektedir.

Çizelge 1. Reşadiye ve çevresinde etnobotanik kullanıma sahip taksonlar

\begin{tabular}{|c|c|c|c|}
\hline Bilimsel Ad & Yerel Ad & Kullanılan Organ & Kullanım Amacı \\
\hline \multicolumn{4}{|l|}{ Amaranthaceae } \\
\hline *Spinacia oleracea & Ispanak & Yaprak & Gıda \\
\hline${ }^{*}$ Beta vulgaris & Pezük, Pazı & Yaprak & Gıda \\
\hline $\begin{array}{l}\text { Chenopodium album subsp. album } \\
\text { var. microphyllum } \\
\text { Amaryllidaceae }\end{array}$ & Unluca & Yaprak ve Gövde & Gıda \\
\hline *Allium cepa & Soğan & Gövde & Gıda, tıbbi \\
\hline *Allium sativum & Sarımsak & Gövde & Gıda, tıbbi \\
\hline \multicolumn{4}{|l|}{ Anacardiaceae } \\
\hline Pistacia terebinthus & Çetene & Meyve, Tohum & Gıda \\
\hline \multicolumn{4}{|l|}{ Apiaceae } \\
\hline Coriandrum sativum & Kişniş otu, Kişniş & Yaprak ve Gövde & Gıda \\
\hline *Petroselinum crispum & Maydanoz, Maydenüs & Yaprak ve Gövde & Gıda, tıbbi \\
\hline \multicolumn{4}{|l|}{ Asparagaceae } \\
\hline Muscari armeniacum & Karga soğanı & Yaprak & Gıda \\
\hline Ornithogalum narbonense & Çiğdem & Kök & Gıda \\
\hline Scilla bifolia & Sümbül & Çiçek & Süs bitkisi \\
\hline \multicolumn{4}{|l|}{ Asteraceae } \\
\hline *Lactuca sativa & Marul & Yaprak & Gıda \\
\hline Anthemis arvensis & Papatya, Koyungözü & Yaprak, Çiçek ve Gövde & Tibbi \\
\hline Tragopogon aureus & Tekesakalı, Yelmik & Yaprak ve Gövde & Gıda \\
\hline Scorzonera cana var. jacquiniana & Tekesakalı & Yaprak ve Gövde & Gıda \\
\hline Tussilago farfara & Kabalak & Yaprak & Tıbbi \\
\hline \multicolumn{4}{|l|}{ Betulaceae } \\
\hline Carpinus betulus & Gürgen & Gövde & Yakacak \\
\hline${ }^{*}$ Corylus avellana subsp. avellana & Fındık & Meyve ve Yaprak & Gıda \\
\hline \multicolumn{4}{|l|}{ Boraginaceae } \\
\hline Lithospermum purpurocaeruleum & Taşkesen & Yaprak & Tıbbi \\
\hline Trachystemon orientalis & Kaldırık & Yaprak ve Gövde & Gıda \\
\hline $\begin{array}{lll}\text { Anchusa } & \text { leptophylla } & \text { subsp. } \\
\text { leptophylla } & & \end{array}$ & Dikencik & Yaprak ve Gövde & Gıda, tıbbi \\
\hline \multicolumn{4}{|l|}{ Brassicaceae } \\
\hline Capsella bursa-pastoris & $\begin{array}{l}\text { Çobançantası, Çoban } \\
\text { ekmeği }\end{array}$ & Yaprak ve Gövde & Gıda \\
\hline *Brassica oleracea & Kara lahana & Yaprak & Gıda, tıbbi \\
\hline *Lepidium sativum & Tere otu & Tüm bitki & Gıda \\
\hline Sinapis alba & $\begin{array}{l}\text { Manuk, Manık, Hardal } \\
\text { otu }\end{array}$ & Yaprak ve Gövde & Gıda \\
\hline
\end{tabular}


Çizelge 1. (Devam)

\begin{tabular}{|c|c|c|c|}
\hline Bilimsel Ad & Yerel Ad & Kullanilan Organ & Kullanım Amacı \\
\hline $\begin{array}{r}\text { Raphanus raphanistrum } \\
\text { Cannabaceae }\end{array}$ & Turpluk, Turp & Yumru & Gıda, tıbbi \\
\hline Cannabis sativa & Kendir & Yaprak ve Gövde & $\begin{array}{l}\text { İp yapmak için } \\
\text { kullanılır. }\end{array}$ \\
\hline $\begin{array}{l}\text { Celtis tournefortii } \\
\text { Caryophyllaceae }\end{array}$ & Davum & Meyve & Gıda \\
\hline Stellaria media var. media & Hevdidik & Yaprak ve Gövde & Gıda \\
\hline Dianthus calocephalus & Orman karanfili & Çiçek & Süs bitkisi \\
\hline Silene alba subsp. eriocalycina & $\begin{array}{l}\text { GıCl, Gıcıoğlak, } \\
\text { Cincioğlak, Kırcıoğlak }\end{array}$ & Yaprak & Gıda, tıbbi \\
\hline Colchicaceae & & & \\
\hline $\begin{array}{r}\text { Colchicum falcifolium } \\
\text { Cornaceae }\end{array}$ & Çiğdem & Gövde & Gıda \\
\hline $\begin{array}{l}\text { Cornus mas } \\
\text { Cucurbitaceae }\end{array}$ & Kiren & Meyve & Gıda, tıbbi \\
\hline $\begin{array}{l}{ }^{*} \text { Cucumis sativus } \\
\text { Cupressaceae }\end{array}$ & Salatalık & Meyve & Gıda \\
\hline Juniperus oxycedrus & Ardıç & Meyve & $\begin{array}{l}\text { Tıbbi, hayvan } \\
\text { rahatsızlığı, yakacak }\end{array}$ \\
\hline $\begin{array}{l}\text { Fabaceae } \\
\text { *Phaseolus vulgaris }\end{array}$ & Fasulye, Böğrülce & Meyve, Yaprak, Tohum & Gıda \\
\hline Fagaceae & & & \\
\hline $\begin{array}{l}\text { Quercus coccifera } \\
\text { Gentianaceae }\end{array}$ & Meşe & Gövde ve Yaprak & $\begin{array}{l}\text { Hayvan yemi, } \\
\text { yakacak }\end{array}$ \\
\hline $\begin{array}{c}\text { Gentiana verna subsp. pontica } \\
\text { Grossulariaceae }\end{array}$ & Dağ çiçeği & Çiçek & Arıcılık \\
\hline $\begin{array}{l}\text { Ribes nigrum } \\
\text { Juncaceae }\end{array}$ & Civek & Yaprak & Gıda, arıcılık \\
\hline $\begin{array}{l}\text { Luzula spicata } \\
\text { Juglandaceae }\end{array}$ & Orman çiçeği & Çiçek & Arıcılık \\
\hline $\begin{array}{l}\text { *Juglans regia } \\
\text { Lamiaceae }\end{array}$ & Ceviz & Meyve & Gıda \\
\hline Lamium maculatum & Adaçayı & Tüm bitki & Tibbi \\
\hline Mentha aquatica & Narpuz, Dağ nanesi & Yaprak & Baharat \\
\hline $\begin{array}{l}\text { Mentha longifolium subsp. } \\
\text { longifolium }\end{array}$ & Nane & Yaprak & Tibbi \\
\hline Mentha piperita & Narpuz, nane & Yaprak & Tıbbi, baharat \\
\hline $\begin{array}{l}\text { Thymus vulgaris } \\
\text { Lilliaceae }\end{array}$ & Kekik & Yaprak, çiçek & Tıbbi, baharat \\
\hline $\begin{array}{l}\text { Gagea taurica } \\
\text { Malvaceae }\end{array}$ & Orman çiçeği & Çiçek & Arıcılık \\
\hline Malva neglecta & $\begin{array}{l}\text { Kömeç, Gömeç, Ebe } \\
\text { gömeci }\end{array}$ & Yaprak & Gıda, tıbbi \\
\hline $\begin{array}{c}\text { Tilia rubra subsp. caucasica } \\
\text { Moraceae }\end{array}$ & Ihlamur & Çiçek ve Yaprak & Tibbi \\
\hline $\begin{array}{l}{ }^{*} \text { Morus alba } \\
\text { Onagraceae }\end{array}$ & Dut & Meyve & Gıda, tıbbi \\
\hline $\begin{array}{l}\text { Epilobium parviflorum } \\
\text { Orchidaceae }\end{array}$ & Yer sakızı & Yumru & Tibbi \\
\hline Dactylorhiza romana subsp. romana & Sahlep & Kök & Ticari, gıda \\
\hline Pedaliaceae & & & \\
\hline *Sesamum indicum & Susam otu & Çiçek, tohum & Baharat \\
\hline
\end{tabular}


Çizelge 1. (Devamı)

\begin{tabular}{|c|c|c|c|}
\hline Bilimsel Ad & Yerel Ad & Kullanılan Organ & Kullanım Amacı \\
\hline \multicolumn{4}{|l|}{ Pinaceae } \\
\hline Pinus brutia & $\begin{array}{l}\text { iliç̧, Kasvuk, Kasmuk, } \\
\text { Kızılçam }\end{array}$ & $\begin{array}{l}\text { Kabuk ile Gövde } \\
\text { arasındaki zarımsı kısım, } \\
\text { Gövde, Kozalak }\end{array}$ & $\begin{array}{l}\text { Tıbbi, yakacak, yapı } \\
\text { malzemesi. }\end{array}$ \\
\hline \multicolumn{4}{|l|}{ Plantaginaceae } \\
\hline Plantago major & $\begin{array}{l}\text { Sinirli ot, Sinirli yaprak, } \\
\text { Kesik otu }\end{array}$ & Yaprak & Tıbbi \\
\hline Veronica polita & Cüce bağırsığı & Gövde ve Yaprak & Gıda \\
\hline \multicolumn{4}{|l|}{ Poaceae } \\
\hline Hordeum vulgare & Arpa & Başak & Ritüel tedavi \\
\hline \multicolumn{4}{|l|}{ Polygonaceae } \\
\hline Rumex crispus & Efelik, efelek & Yaprak & Gıda \\
\hline Polygonum cognatum & Madımak & Yaprak ve Gövde & Gıda. \\
\hline Polygonum aviculare & Kuşekmeği & Yaprak ve Gövde & Gıda \\
\hline \multicolumn{4}{|l|}{ Portulaceae } \\
\hline Portulaca oleracea & pürpürün, & Yaprak ve Gövde & Gıda \\
\hline \multicolumn{4}{|l|}{ Ranunculaceae } \\
\hline Helleborus orientalis & Dağ çiçeği & Çiçek & Arıcilık \\
\hline \multicolumn{4}{|l|}{ Rosaceae } \\
\hline Alchemilla vulgaris & Domuz ağırşağı & Kök & Tıbbi \\
\hline${ }^{*}$ Cydonia oblonga & Ayva & Meyve & Gıda, tıbbi \\
\hline${ }^{*}$ Cerasus avium & Kiraz & Meyve & Gıda, tıbbi \\
\hline Cerasus padus & Kuş Kirazı & Meyve & Gıda \\
\hline Cerasus vulgaris & Vişne & Meyve & Gıda \\
\hline Crataegus monogyna & Alıç & Meyve & Gıda, tıbbi \\
\hline Fragaria vesca & Yabani Çilek & Meyve & Gıda \\
\hline *Malus sylvestris var. mitis & Elma & Meyve & Gıda \\
\hline *Pyracantha coccinea & Tavşan elması & Meyve & Gıda \\
\hline *Prunus domestica & Erik & Meyve & Gıda \\
\hline Prunus mahaleb & Mehlep & Meyve ve Gövde & Gıda, tıbbi, yakacak \\
\hline${ }^{*}$ Pyrus communis subsp. communis & Armut & Meyve & Gıda \\
\hline Pyrus elaeagnifolia & Ahlat, Çördük & Meyve & Gıda, tıbbi \\
\hline Rosa canina & Kuşburnu, Gülburnu & Meyve, yaprak & Gıda, tıbbi \\
\hline Rubus discolor & Böğürtlen & Meyve ve Yaprak & Gıda \\
\hline \multicolumn{4}{|l|}{ Salicaceae } \\
\hline Populus nigra & Kavak & Gövde & Yapı malzemesi \\
\hline \multicolumn{4}{|l|}{ Santalaceae } \\
\hline Viscum album subsp. album & Kökçe, Gökçe & Bütün bitki & Tıbbi \\
\hline \multicolumn{4}{|l|}{ Solanaceae } \\
\hline Solanum tuberosum & Patates & Gövde & Gıda, tıbbi \\
\hline${ }^{*}$ Capsicum annuum & Biber & Meyve & Gıda \\
\hline Lycopersicon esculentum & Domates & Meyve & Gıda \\
\hline \multicolumn{4}{|l|}{ Urticaceae } \\
\hline Urtica urens & Isırgan & Yaprak, gövde & Gıda, tıbbi, bakım \\
\hline \multicolumn{4}{|l|}{ Vitaceae } \\
\hline *Vitis vinifera & Tevek & Yaprak ve Meyve & Gıda \\
\hline
\end{tabular}

*Kültür bitkileri

Bitkilerin kullanılan organlara göre dağılımı çiçek 11 (\%13), gövde 32 (\%38), kozalak
1 (\%1), kök 7 (\%8), meyve 26 (\%31), tohum 3 (\%4), bütün bitki $3(\% 4)$, yaprak 43 (\%51)'tür 
(Şekil 5). Bu sonuçlara göre yaprak ve gövde en çok kullanılan organlar olarak tespit edilmiştir. Bitkilerin daha çok gıda olarak kullanılması ve yemeklerin standart şekilde pişirildiği göz önüne alındığında gövde ve yaprağın en çok kullanıma sahip organlar olması kaçınılmazdır. Kullanılan organlara göre dağılımda önemli yer kaplayan bir diğer organ ise meyvedir. Bunun nedeni ise familya düzeyinde en çok kullanıma sahip olan Rosaceae üyelerinin tamamının meyve amaçlı kullanılmasıdır. Meyvenin gerek doğal, gerekse kültür olarak çok yaygın olması kullanım oranını yüksek kılmaktadır.

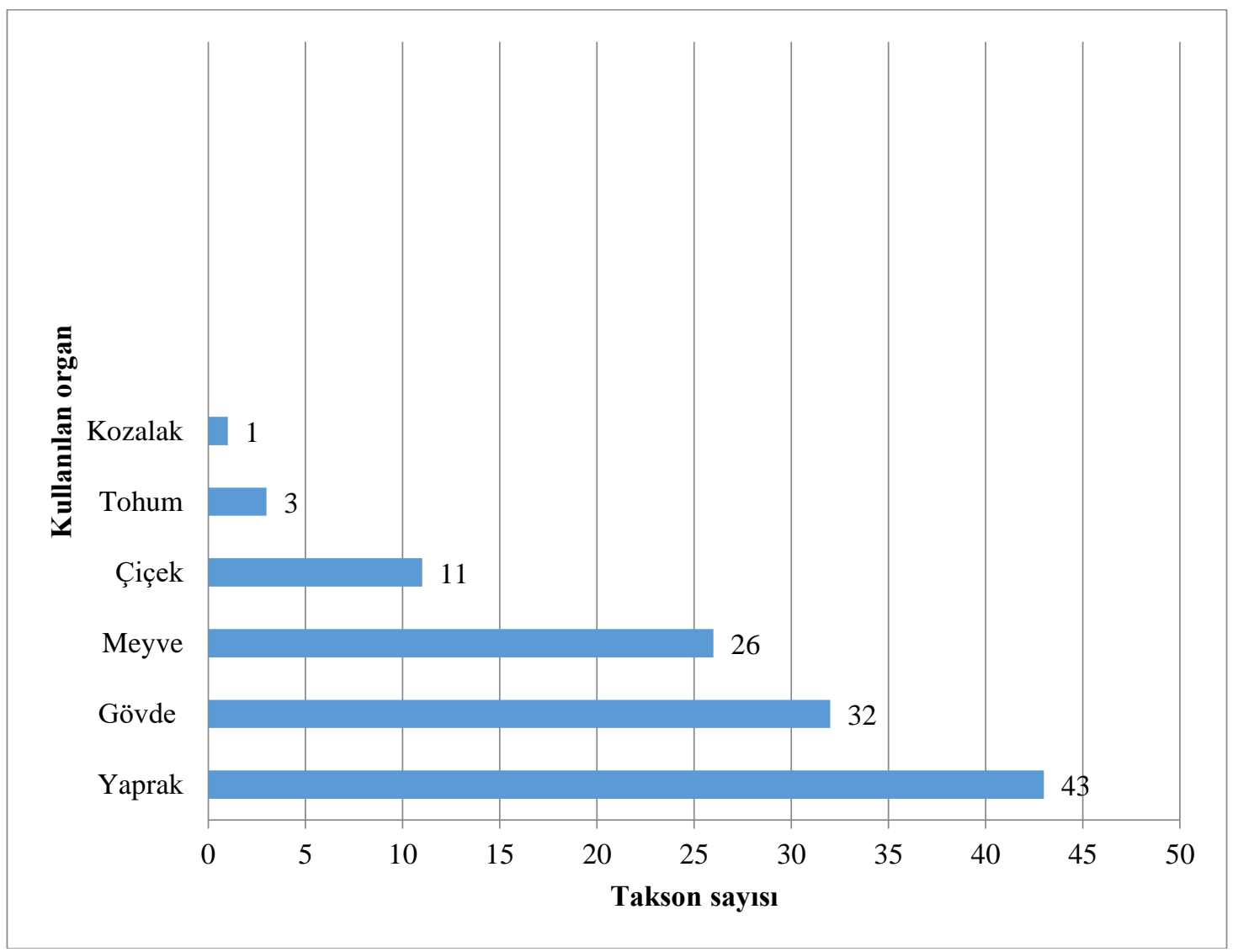

Şekil 5. Kullanılan organa göre takson sayısının dağılımı.

Bilgi kaynağı olan kaynak kişiler ağırlıklı olarak 41-60 yaş arası (\%41) olup, genellikle ilkokul mezunu (\%48), çoğu evli (\%97.5), çiftçi daha çok (\%29), büyük bir kısmı yörede 10 yıldan fazla yerleşiktir (\%84) ve çoğunluğu erkektir (\%91).

Kaynak kişilerin bitkileri kullanım amaçları içinde gıda amaçı kullanımın ağırlıkta olduğu belirlenmiş olup, bunu tıbbi amaçlı kullanım izlemektedir.

Gıda olarak kullanılan 61 bitki taksonunun, kaynak kişilerin yaşı ile orantısal ilişkisi incelenmiş ve kişilerin yaşı arttıkça gıda olarak kullanılan bitki sayısının da arttığı gözlemlenmiştir ' $<20$ ' yaş grubunda bitki kullanımı hiç yokken, "21-40" yaş grubunda \%12.5, “41-60" yaş grubunda \%38.6 ve "61>” yaş grubunda \%48.9'dır (Çizelge 2). Yaşlı insanların geçmişten gelen geleneksel bitki kullanım bilgisini ve yaşantısını sürdürdüğü, ancak ilgi azlığı nedeniyle genç bireylere aktarmakta sıkıntı çektiği, bu yüzden yaş oranının düştükçe bitki kullanımının da azaldığı düşünülmektedir. 
Çizelge 2: Kaynak kişilerin yaş, cinsiyet, eğitim, evlilik, iş, yerleşim ve ikamet bilgileri

\begin{tabular}{|c|c|c|}
\hline Kaynak Kişilerin Yaş Dağılımı & Sayısı & Yüzdesi \\
\hline $1-20$ Arası & 0 & $\% 0$ \\
\hline $21-40$ Arası & 16 & $\% 13$ \\
\hline $41-60$ Arası & 49 & $\% 41$ \\
\hline 61 ve Üstü & 55 & $\% 46$ \\
\hline \multicolumn{3}{|l|}{ Eğitim Seviyeleri } \\
\hline Okur-yazar değil & 6 & $\% 5$ \\
\hline İlkokul Mezunu & 58 & $\% 48$ \\
\hline Ortaokul Mezunu & 29 & $\% 24$ \\
\hline Lise Mezunu & 26 & $\% 22$ \\
\hline Üniversite Mezunu & 1 & $\% 1$ \\
\hline \multicolumn{3}{|l|}{ Evlilik Durumları } \\
\hline Evli & 117 & $\% 97,5$ \\
\hline Bekar & 1 & $\% 0,85$ \\
\hline Dul & 2 & $\% 1,65$ \\
\hline \multicolumn{3}{|l|}{ İş Durumu } \\
\hline Çiftçi & 38 & $\% 29$ \\
\hline Ev Hanımı & 11 & $\% 9$ \\
\hline Emekli & 40 & $\% 31$ \\
\hline Memur & 2 & $\% 2$ \\
\hline İşçi & 4 & $\% 3$ \\
\hline Diğer & 34 & $\% 26$ \\
\hline \multicolumn{3}{|l|}{ Yerleşim Yeri } \\
\hline Belde veya Belediye & 38 & $\% 31,5$ \\
\hline Köy & 82 & $\% 68,5$ \\
\hline \multicolumn{3}{|l|}{ İkamet Süresi } \\
\hline 10 yıldan fazla & 101 & $\% 84$ \\
\hline 10 yıldan az & 19 & $\% 16$ \\
\hline \multicolumn{3}{|l|}{ Cinsiyet } \\
\hline Erkek & 109 & $\% 91$ \\
\hline Kadın & 11 & $\% 9$ \\
\hline
\end{tabular}

Araştırma sonuçlarına göre 40 familyaya ait 85 takson tek ya da çok amaçlı olarak kullanılmaktadır. Kaynak kişilerin bitkileri kullanımı 27 ile 81 yaş arasında dağılım göstermektedir. Yapılan Kendall - Tau regresyon analizinde yaş grupları ile bitki kullanım amacı arasındaki önemli fark bulunmuştur (F: 101.109; $\mathrm{P}<0.05$ ) (Çizelge 3). Ayrıca, yaş ilerledikçe bitki kullanımı artmaktadır (R2:0.881; P<0.05) (Şekil 6).

Çizelge 3. Kendall - Tau Regresyon analizi

\begin{tabular}{cccccccc} 
Eşitlik & $\mathrm{R}^{2}$ & $\mathrm{~F}$ & $\mathrm{df1}$ & $\mathrm{df2}$ & $\mathrm{P}$ & Constant & $\mathrm{b} 1$ \\
\hline & & & & & & & \\
Linear & 0.981 & 101.109 & 1 & 2 & 0.010 & -125.500 & 118.200 \\
\hline
\end{tabular}

R: Korelâsyon katsayısı df: Serbestlik derecesi P: Test önemlilik olasılığı 


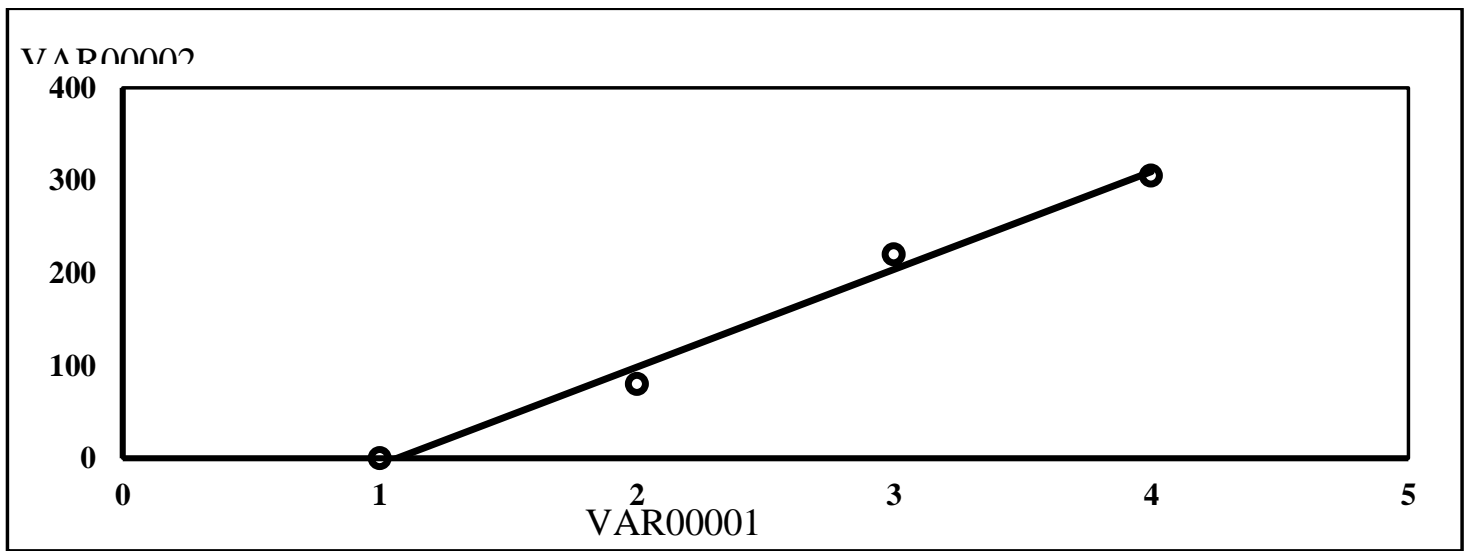

Şekil 6. Regresyon analizi grafiği (VAR00001: Yaş grupları, VAR00002: Bitki kullanım sayısı).

Arazi çalışması boyunca yörede yaşayan 120 kaynak kişiye başvurulmuştur. Kaynak kişilerin toplumsal konumları dikkate alındığında bölgede yaşayan insanların büyük çoğunluğunun ilkokul mezunu olduğu, bunu ortaokul ve lisenin takip ettiği görünmektedir. Okumamış ve üniversite mezun sayısının oldukça az olduğu gözlenmiştir. Kaynak kişiler arasında evli olmayan (bekâr veya dul) sayısı yok denecek kadar azdır ve etnobotanik konusunda bilgi alınanların neredeyse tamamı evli erkeklerden oluşmaktadır. Ancak arazide bitki toplayanların önemli bölümü kadın olmakla birlikte, iletişimden uzak olmaları nedeniyle bilgiler erkekler tarafından aktarılmaktadır. Kaynak kişilerin büyük bir çoğunluğu emekli ve çiftçiler den oluşmaktadır. Emekli olanların konuya ilgileri ve daha fazla zaman bulmaları nedeniyle, çiftçilerin ise tarım ile uğraşmalarının yanında bitkiler ile olan ilişkileri konusunda duyarlı olmalarından kaynaklandığı düşünülmektedir. Kaynak kişilerin çoğunluğu köylerde yaşamaktadır ve uzun yıllardır bu bölgede ikamet etmektedirler. Bu durumda hem yöreyi daha iyi tanıdıkları ve hem de yerel kültürleri geçmişten bugüne taşımaları nedeniyle bitkiler ile yakın ilişki halinde oldukları sonucunu çıkmaktadır.

\section{Sonuç ve Öneriler}

Etnobotanik araştırmamızda elde edilen sonuçlar bitki kullanımı anlamında dikkate alınıp bugüne kadar yapılan araştırma sonuçları ile karşılaştırıldığında 63 taksonun kullanım amaçlarının benzerlik gösterdiği gözlenmiştir. Etnobotanik kullanım açısından benzerlik gösteren taksonlar; Allium cepa L., Allium sativum L., Anchusa leptophylla Roem. \&
Schult., Beta vulgaris L., Brassica oleracea L., Capsella bursa-pastoris (L.) Medik., Capsicum annuum L., Carpinus betulus L., Cerasus avium (L.) Moench, Cerasus padus (L.) DC., Cerasus vulgaris Mill., Celtis tournefortii Lam., Chenopodium album L. subsp. album var. microphyllum, Coriandrum sativum L., Cornus mas L., Corylus avellana L. subsp. avellana, Crataegus monogyna Jacq., Cucumis sativus L., Cydonia oblonga Mill. , Fragaria vesca L., Juglans regia L., Juniperus oxycedrus L., Lactuca sativa L, Lepidium sativum L., Lycopersicon esculentum Mill., Malus sylvestris var. mitis (L.) Mill., Malva neglecta Wallr., Mentha aquatica L., Mentha longifolia (L.) L., Mentha x piperita L., Morus alba L., Petroselinum crispum (Mill.) Fuss, Pinus brutia Ten., Pistacia terebinthus L., Quercus coccifera L., Ribes nigrum L., Phaseolus vulgaris L., Plantago major L., Polygonum aviculare L., Polygonum cognatum Meisn., Populus nigra L., Portulaca oleracea L., Prunus domestica L., Pyracantha coccinea M. Roem., Pyrus communis L. subsp. communis, Pyrus elaeagnifolia Pall., Raphanus raphanistrum L., Rosa canina L., Rubus discolor Boiss., Rumex crispus L., Scilla bifolia L., Sesamum indicum L., Sinapis alba L., Solanum tuberosum L., Spinacia oleracea L., Stellaria media (L.) Vill., Thymus vulgaris L., Tilia rubra subsp. caucasica (Rupr.) V. Engl., Trachystemon orientalis (L.) D. Don, Tragopogon auresus Boiss., Urtica urens L., Viscum album L. ve Vitis vinifera L. olup, diğer yayınlarda da ortak sonuçlar olarak değerlendirilebilir. Bu bitkilerin 22 tanesi kültür bitkisidir ve Reşadiye yöresinde yetişen bitkilerin \%26'sını oluşturmaktadır.

Araştırmamız ağırlıklı olarak halkın bitkilerden daha çok gıda amaçlı yararlandığını 
göstermiştir. Bu bağlamda araştırma bölgemize yakın illerde yapılan çalışmalara bakıldığında; bitkilerden ağırıklı olarak gıda amaçı faydalanıldığı görülmüştür. Sarıkaya ve Karaevli (2019) Ordu'nun Korgan ilçesinde doğal yayılış gösteren etnobotanik kullanıma sahip 23 taksondan 13'ünün çay, 2'sinin baharat, 2'sinin süs bitkisi, 12'sinin gıda amaçlı kullanıldığını tespit etmiş, bu bitkilerden sadece Tussilago farfara, Capsella bursa-pastoris, Chenopodium album, Fragaria vesca ve Plantago major'un Reşadiye yöresinde yaptığımız çalışma ile ortak olduğu görülmüştür. Ayrıca bitkilerin en fazla kullanılan organlarının yapraklar olması ile de çalışmamız ile benzerlik göstermektedir. Türkan ve ark. (2006)'nin Ordu ili ve çevresinde gıda ve tedavi amaçlı kullanılan bitkileri araştırdıkları çalışmada 18 familyaya ait 35 türden yerel halkın ağırlıklı olarak gıda amaçlı faydalandıkları saptanmış, Allium sativum, Capsella bursapastoris, Crateagus monogyna, Cydonia oblonga, Fragaria vesca, Juglans regia, Morus alba, Pyrus communis, Tilia rubra ve Tussilago farfara bitkilerinin çalışmamı ile benzer kullanım amaçları ile kullanıldığı görülmüştür. Gül (2014) tarafından Rize ilinin 5 ilçesinde yapılan tıbbi amaçlı kullanılan 42 bitkinin etkisi ve kullanım şekillerinin ortaya konduğu araştırmada yer alan bitkilerden Mentha piperita, Plantago major ve Tilia rubra'nın hem kullanım amacı hem de kullanım şekli bakımından çalışmamız ile benzerlik gösterdiği, Rize'de tıbbi amaçlı kullanılan Helleborus orientalis bitkisinin Reşadiye'de ise arıcılıkta kullanıldığı görülmüştür. Tussilago farfara'nın Rize'de kullanım şeklinin Reşadiye yöresinden farklılık gösterip kullanım amacı ile benzerlik gösterdiği görülmüştür. Saraç (2013) tarafından Rize ilinde yapılan çalışmada 113 taksondan 78'inin tıbbi, 43'ünün ise gıda amaçlı kullanıldığı belirtilmiş, ağırlıklı olarak tıbbi bitkilerin kullanılması bakımından çalışmamız ile farklıık gösterdiği görülmüştür.

Araştırma bulgularında bugüne kadar yapılmış diğer araştırmalardan farklı olarak 22 taksonun orijinal etnobotanik kullanım şekilleri belirlenmiştir. Bu bitkilerden; Alchemilla vulgaris L. ve Alkanna orientalis (L.) Boiss. yanık tedavisinde,, Anthemis arvensis L. romatizmal ağrılarda, Cannabis sativa L. ip yapmak amaçlı, Colchicum falcifolium Staph. gıda olarak, Dactylorhiza romana subsp. romana (Sebast.) Soó ticari amaçla, Dianthus calocephalus Boiss. süs bitkisi olarak, Epilobium parviflorum Schreb. hazım kolaylaştırıcı olarak, Gagea taurica
Steven, Gentiana verna subsp. pontica (Soltok.) Hayek ve Helleborus orientalis Lam. arıcılıkta, Hordeum vulgare L. sedef hastalığı tedavisinde, Lamium maculatum (L.) L. göğüs yumuşatıcı olarak, Lithospermum purpurocaeruleum L. idrar söktürücü olarak, Luzula spicata (L.) DC. arıcılıkta, Muscari armeniacum Leichtlin ex Baker ve Ornithogalum narbonense L. gida olarak, Prunus mahaleb L. güneş çarpması tedavisinde ve yakacak olarak, Scorzonera cana var. jacquiniana (W.Koch) D.F.Chamb. gıda olarak, Silene alba subsp. eriocalycina (Mill.) E.H.L.Krause şeker düşürmede, Tussilago farfara L. güneş çarpmasında ve Veronica polita Fr. gıda olarak kullanılmakta olup, elde edilen sonuçların güvenilirliğinin artırılması için yeni araştırmalar ile desteklenmesi gereklidir. Bu sayede ulaştığımız bulgular genişletilerek özellikle yakın çevre bazında yeni araştırmalarla güçlendirilip daha sağlıklı sonuçlara ulaşılacaktır. Bu taksonlara ait familyalar; Asparagaceae, Asteraceae, Boraginaceae, Cannabaceae, Caryophyllaceae, Colchicaceae, Gentianaceae, Juncaceae, Lamiaceae, Lilliaceae, Onagraceae, Orchidaceae, Plantaginaceae, Poaceae, Ranunculaceae, Rosaceae olup bu familyalardaki taksonların ağırlıklı kullanımı tıbbi olmaktadır.

Orijinal kullanıma sahip ve tedavi amaçlı kullanılan olan taksonların değerlendirilmesi ve daha nitelikli sonuçlara ulaşılabilmesi için bu bitkilerdeki etken maddelerin belirlenmesi, farmakolojik çalışmalar ile mümkün olabilecektir. Böylece elde edilen sonuçlar ile yöresel ekonomiye destek vermek amacı ile değerlendirilmesi, ekonomik olarak zayıf olan bölgeye bir canlılık getirecektir. Olumlu sonuçlar alınan bitkilerin üretiminin yaygınlaştırılması ve tüketime sunulması yöre halkı için önemli bir ekonomik gelir kaynağı oluşturabilecektir.

${ }^{\sharp} \mathrm{Bu}$ araştırma makalesinde Erkan YÜZBAŞıOĞLU'nun Çanakkale Onsekiz Mart Üniversitesi, Fen Bilimleri Enstitüsü, Biyoloji Anabilim Dalı'nda yapmış olduğu yüksek lisans tezinden yararlanılmıştır.

\section{Kaynaklar}

Bayrak, Özbucak T., Kutbay, H.G. ve Ergen Akcin, Ö. 2006. The Contribution of Wild Edible Plants to Human Nutrition in the Black Sea Region of Turkey, Ethnobotanical Leaflets, 10: 98-103. 
Baytop, T. 1999. Türkiye'de Bitkilerle Tedavi Geçmişte ve Bugün. Nobel Tıp Kitabevleri, II. Baskı, İstanbul, 480s.

Çolakoğlu, M. ve Tömek, S. 1975. Ege Bölgesinde Bazı Yenebilen Otların Bileşimleri. Ege Üniversitesi Ziraat Fakültesi Yayınları. No: 228, İzmir.

Davis, P.H. 1985. Flora of Turkey and the East Aegean Islands. Ed: Davis P.H., Vol. 1 -9., Edinburgh University Press, Edinburgh.

Davis, P.H., Mill R.R. ve Tan K. 1998. Flora of Turkey and the East Aegean Islands Vol. 10. Edinburgh University Press, Edinburgh.

Ertuğ, F. 2000. An Ethnobotanical Study in Central Anatolia (TURKEY). Economic Botany. 54 (2) pp., New York Botanical Garden Press, Bronx, 155-182.

Ertuğ Yaraş, F. 1996. Contemporary Plant Gathering in Central Anatolia: An Ethnoarchaeological and Ethnobotanical Study. Plant Life in Southwest and Central Asia. Proceedings of the IVth Plant Life in Southwest Asia Symposium, 21-28 Mayıs 1995, Ege Üniversitesi Yayınları, İzmir, s. 945-962.

Fakir, H., Korkmaz M. ve Güller, B. 2009. Medicinal Plant Diversity of Western Mediterrenean Region in Turkey. Journal of Applied Biological Sciences, 3 (2):3040.

Farnsworth, N.R. 1990. The Role of Ethnopharmacology in Drug Development. In: Chadwick, DJ., Marsh, J. (ed.)., John Wiley \& Sons Ltd., West Sussex; Bioactive Compounds from Plants. 2-21.

Gül, V. 2014. Rize Yöresine Ait Tıbbi ve Aromatik Bitkilere Genel Bir Bakış. Iğdır Üniversitesi Fen Bilimleri Enstitüsü Dergisi, 4 (4): 97107.

Güner, A., Aslan S., Ekim T., Vural M. ve Babaç M.T. (edlr.) 2012. Türkiye Bitkileri Listesi (Damarlı Bitkiler). Nezahat Gökyiğit Botanik Bahçesi ve Flora Araştırmaları Derneği Yayını, İstanbul.

Ospankulava, E. 2005. Türkiye Etnobotanik Araştırmalar Veri Tabanı. İstanbul Üniversitesi, Sağlık Bilimleri Enstitüsü, Farmasötik Botanik Anabilim Dalı, Yüksek Lisans Tezi, İstanbul.

Öztürk, M. ve Özçelik, H. 1991. Doğu Anadolu'nun Faydalı Bitkileri. SISKAV Yayınları, Ankara.
Sadıkoğlu, N. 1998. Cumhuriyet Dönemi Türk Etnobotanik Araştırmalar Arşivi. İstanbul Üniversitesi, Sağlık Bilimleri Enstitüsü, Yüksek Lisans Tezi, İstanbul.

Saraç, D.í. 2013. Rize ili Etnobotanik Özellikleri. Karadeniz Teknik Üniversitesi, Orman Mühendisliği Anabilim Dalı, Yüksek Lisans Tezi, Trabzon.

Sarıkaya, A.G. ve Karaevli, A. 2019. Korgan (Ordu) Yöresinde Doğal Yayılış Gösteren Bitki Taksonlarının Etnobotanik Özellikleri. Türkiye Ormancılık Dergisi, 20(3): 173-179.

Saygılı, R. 2015. Harita Bilgisi Ders Notları 2. http://cografyaharita.com.

Türkan, Ş., Malyer, H. ve Özaydın, S. 2006. Ordu ìli ve Çevresinde Yetişen Bazı Bitkilerin Etnobotanik Özellikleri. Süleyman Demirel Üniversitesi Fen Bilimleri Enstitüsü Dergisi, 10-02: 162-166.

Ulcay, S. ve Şenel, G. 2020. Tokat Çevresinde Yayılış Gösteren Bazı Tıbbi ve Yenilebilir Bitkilerin Etnobotanik Özelliklerinin Belirlenmesi Üzerine Bir Araştırma. Academic Platform Journal of Engineering and Science, 8-1, 62-69.

Wickens, G. E. 1990. What is Economic Botany?, Economic Botany, 44 (1) pp.,12-28, The New york Botanic Garden Press, Bronx.

Yıldırımlı, Ş. 2004. Etnobotanik ve Türk Etnobotaniği. Kebikeç Insan Bilimleri için Kaynak Araştırmaları Dergisi, 17, s. 175193.

Yüzbaşıŏ̆lu, E., 2010. Reşadiye (A6, Tokat, Türkiye) ve Çevresinin Etnobotaniği. Çanakkale Onsekiz Mart Üniversitesi, Fen Bilimleri Enstitüsü, Biyoloji Anabilim Dalı, Yüksek Lisans Tezi, Çanakkale. 